Article

\title{
Variation of DNA Methylation in Newborns Associated with Exhaled Carbon Monoxide during Pregnancy
}

\author{
Ediane De Queiroz Andrade 1,2 ${ }^{\mathbb{D}}$, Gabriela Martins Costa Gomes ${ }^{1,2}$, Adam Collison 1,2,*, Jane Grehan ${ }^{1,2}$, \\ Vanessa E. Murphy ${ }^{1,2}$, Peter Gibson ${ }^{3,4}$, Joerg Mattes ${ }^{1,2,5}$ and Wilfried Karmaus ${ }^{6, *(D)}$
}

1 School of Medicine and Public Health, University of Newcastle, Newcastle, NSW 2308, Australia; ediane.dequeirozandrade@uon.edu.au (E.D.Q.A.); gabriela.martinscostagomes@uon.edu.au (G.M.C.G.); jane.grehan@newcastle.edu.au (J.G.); vanessa.murphy@newcastle.edu.au (V.E.M.); joerg.mattes@newcastle.edu.au (J.M.)

2 Priority Research Centre GrowUpWell, Hunter Medical Research Institute, University of Newcastle, Newcastle, NSW 2308, Australia

3 Priority Research Centre Healthy Lungs, Hunter Medical Research Institute, University of Newcastle, Newcastle, NSW 2308, Australia; peter.gibson@newcastle.edu.au

4 Respiratory \& Sleep Medicine Department, John Hunter Hospital, Newcastle, NSW 2305, Australia

5 Paediatric Respiratory \& Sleep Medicine Department, John Hunter Children's Hospital, Newcastle, NSW 2305, Australia

6 Division of Epidemiology, Biostatistics, and Environmental Health Science, School of Public Health, The University of Memphis, Memphis, TN 38152, USA

* Correspondence: adam.collison@newcastle.edu.au (A.C.); karmaus1@memphis.edu (W.K.); Tel.: +61-2-4042-0219 (A.C.); +1-901-678-2491 (W.K.)

check for updates

Citation: De Queiroz Andrade, E.; Gomes, G.M.C.; Collison, A.; Grehan, J.; Murphy, V.E.; Gibson, P.; Mattes, J.; Karmaus, W. Variation of DNA Methylation in Newborns Associated with Exhaled Carbon Monoxide during Pregnancy. Int. J. Environ. Res. Public Health 2021, 18, 1597.

https: / / doi.org/

10.3390/ijerph18041597

Academic Editor: Farren B. S. Briggs Received: 24 November 2020

Accepted: 1 February 2021

Published: 8 February 2021

Publisher's Note: MDPI stays neutral with regard to jurisdictional claims in published maps and institutional affiliations.

Copyright: (c) 2021 by the authors Licensee MDPI, Basel, Switzerland. This article is an open access article distributed under the terms and conditions of the Creative Commons Attribution (CC BY) license (https:/ / creativecommons.org/licenses/by/ $4.0 /)$.

\begin{abstract}
Fetal exposure to tobacco smoke is an adverse risk factor for newborns. A plausible mechanism of how this exposure may negatively impact long term health is differential methylation of deoxyribonucleic acid (DNAm) and its relation to birth weight. We examined whether self-reported gestational smoking status and maternal exhaled carbon monoxide $(\mathrm{eCO})$ during early pregnancy were associated with methylation of cytosine by guanines $(\mathrm{CpG})$ sites that themselves predicted birth weight. We focused first on CpGs associated with maternal smoking, and secondly, among these, on CpGs related to birth weight found in another cohort. Then in 94 newborns from the Breathing for Life Trial (BLT) DNAm levels in cord blood were determined using Infinium Methylation EPIC BeadChip measuring $>850 \mathrm{~K}$ CpGs. We regressed $\mathrm{CpGs}$ on eCO and tested via mediation analysis whether CpGs link eCO to birth weight. Nine smoking related CpG sites were significantly associated with birth weight. Among these nine CpGs the methylation of cg02264407 on the LMO7 gene was statistically significant and linked with eCO measurements. eCO greater than six ppm showed a $2.3 \%$ decrease in infant DNAm $(p=0.035)$ on the LMO7 gene. A $1 \%$ decrease in methylation at this site resulted in decreased birth weight by $44.8 \mathrm{~g}(p=0.003)$. None of the nine CpGs tested was associated with self-reported smoking. This is the first study to report potential mediation of DNA methylation, linking eCO measurements during early pregnancy with birth weight.
\end{abstract}

Keywords: maternal exposure; tobacco use; epigenetic epidemiology; fetal programming; epigenomewide association studies

\section{Introduction}

Fetal exposure to tobacco smoke throughout pregnancy is prevalent and a preventable risk for child morbidity and mortality [1,2]. Despite efforts of international health organisations to raise awareness for risk to the developing fetus, at least $15 \%$ to $20 \%$ of mothers do not quit smoking during pregnancy [3]. Previous research has described associations between in utero [4] tobacco smoke exposure with severe neonatal outcomes such as prematurity [5], stillbirth [6], congenital anomalies [7], low birth weight [8], and neonatal mortality [8]. One of the most widely reported effects is on birth weight [9-11]. 
Birth weight is an informative indicator of pregnancy outcome and neonatal health. Both low and high birth weight categories have been linked to adverse health outcomes later in life [12-15]. Numerous epidemiological studies have focused on understanding the early life determinants of changes on the structural and physiological metabolic functions of the fetus [16-19]. Barker et al., who first observed these associations, hypothesised that programmed changes during this critical period of development predispose the fetus to certain postnatal diseases [20].

A plausible mechanism through which exposure to adverse intrauterine conditions may negatively impact long term health is through modulation of deoxyribonucleic acid (DNA) methylation. It has been suggested that the effects of maternal factors during pregnancy on birth weight are exerted through differential methylation of DNA in offspring [21]. A meta-analysis of epigenome-wide association studies (EWAS) on birth weight and neonatal DNA methylation (DNAm) reported that 914 cytosine-phosphate-guanine sites (CpGs) are differentially methylated in association with birth weight [22]. However, due to concurrent measurements of birth weight and DNAm, it remains unclear whether differentially methylated sites represent the effects of lower birth weight or are risk factors for differences in birth weight.

DNAm has a vital role in repressing gene expression by blocking promoters at which activating transcription factors could bind, thereby controlling cell differentiation and embryonic development [23]. Sutter et al. suggested that maternal smoking dysregulates placental methylation in a CpG site-specific way that correlates with modifications in gene expression along signature pathways, leading to a significant reduction in newborn birth weight among the newborn of smokers [24]. Another mode of action of DNAm is regulation of alternative splicing resulting in gene expression of different transcripts [25].

Although previous studies [26,27] have investigated whether DNAm mediates maternal smoking and birth weight, their approach depended on self-reported smoking status. Self-reports are a possible source of information bias and may underestimate associations with maternal smoking [28].

To the best of our knowledge, no study has explored whether the mediation of DNAm after carbon monoxide exposure in early pregnancy would affect birth weight, direct and indirectly. This study aims to investigate CpG methylation in cord blood samples with self-reported maternal smoking during pregnancy and with exhaled carbon monoxide $(\mathrm{eCO})$ as a biochemical marker for current cigarette exposure. To reduce the number of CpG sites to be tested we focused on DNA methylation sites related to smoking as reported by Joubert et al. [29] based on a meta-analysis of multiple studies. Then, to further concentrate, we used the Isle of Wight Birth Cohort (IoW birth cohort) [30] to identify which of the smoking-related CpGs are also associated with birth weight. Second, we analysed a subgroup of 94 infants by investigating DNAm in cord blood samples. We tested associations of known smoking-related $\mathrm{CpG}$ sites with maternal smoking (questionnaire and eCO in specific time-windows). Third, we investigated whether there is a pathway from smoking exposure via DNA methylation (as mediator) to differential birth weights.

\section{Materials and Methods}

\subsection{Study Design}

This investigation focuses on a subsample of infants from the randomised controlled trial (RCT), the Breathing for Life Trial (BLT) [31]. BLT is a multi-center RCT, which recruited pregnant women with current doctor-diagnosed asthma from public hospital antenatal clinics in Newcastle, Sydney, Canberra, and Brisbane. Women were randomised between 12- and 23-weeks' gestation to asthma management guided by fractional exhaled nitric oxide (FeNO) or to usual clinical care. Women $<18$ years of age or with drug/alcohol dependence were excluded. In a sub-group of the participants, cord blood samples were collected after delivery. This study was approved by the Hunter New England Human Research Ethics Committee (Reference Number 12/10/17/3.04, NSW HREC Reference No: HREC/12/ HNE/357), Australia, and participation was based on written informed consent. 
At enrolment, between 12 and 23 weeks gestation, information was collected about sociodemographic characteristics and lifestyle factors, such as self-reported maternal smoking, maternal age, ethnicity, level of education, parity, health status, height, weight, and exhaled carbon monoxide (eCO) (piCO Smokerlyzer Breath CO Monitor, Bedfont, UK). Postcodes were collected at baseline and used for socioeconomic status within state or territory based on the Socioeconomic Index for Areas (SEIFA) percentiles [32]. For those randomised to usual care, only one study visit was provided. Participants randomised to the intervention group had monthly visits until delivery.

After delivery, trained staff blinded to the intervention group extracted information from medical records on gestational age at birth, birth weight, birth length, type of delivery, maternal and neonatal complications.

\subsection{Cord Blood Collection}

Cord blood samples from BLT participants were collected at John Hunter Hospital (New South Wales-Australia) immediately after birth by needle puncture of the umbilical vein after the umbilical cord was detached from the infant. Samples were transferred into EDTA tubes to be processed within six hours.

\subsection{Flow Cytometry Staining}

Cord blood cells were stained in whole blood and subsets were predefined based on specific surface markers as follow: Eosinophils $\left(\mathrm{CD} 45^{+}, \mathrm{CD} 193^{+}, \mathrm{CD} 16^{-}\right)$, Neutrophils $\left(\mathrm{CD}^{+} 5^{+}, \mathrm{CD}_{193^{-}}, \mathrm{CD}^{+} 6^{+}\right), \mathrm{B}$ cells $\left(\mathrm{CD} 14^{-}, \mathrm{CD}^{-}, \mathrm{CD} 19^{+}\right)$, Natural Killer (NK) cells (CD14 ${ }^{-}$, $\left.\mathrm{CD}^{-}, \mathrm{CD}^{+} 6^{+}, \mathrm{CD}^{-} 6^{+}\right)$, lymphocytes TCD4 cells $\left(\mathrm{CD}^{+}{ }^{+}, \alpha \beta \mathrm{T}\right.$-cell receptor $(\mathrm{TCR})^{+}, \mathrm{CD}^{+}$, $\left.\mathrm{CD} 25^{+}, \mathrm{CD} 127^{+}\right)$, lymphocytes TCD8 cells $\left(\mathrm{CD}^{+}, \alpha \beta \mathrm{TCR}^{+}, \mathrm{CD}^{+}, \mathrm{CD} 25^{+}, \mathrm{CD} 127^{+}\right)$and Monocytes $\left(\mathrm{CD}^{-}, \mathrm{CD} 19^{-}, \mathrm{CD}^{-} 6^{-}, \mathrm{CD} 14^{+}, \mathrm{CD}^{+} 6^{+}, \mathrm{HLA}^{-} \mathrm{DR}^{+}\right)$. After 30 min of incubation, red blood cells were lysed using BD FACS ${ }^{\mathrm{TM}}$ Lysing Solution and washed. Samples were stored at $4{ }^{\circ} \mathrm{C}$ until acquisition of LSRFortessa X-20 flow cytometer (BD Biosciences, San Diego, CA, USA). Samples were analysed using FlowJo software (v 10.5-Flow Jo LLC, Ashland, OR, USA).

\subsection{DNA Methylation Analysis}

From other whole blood samples, DNA was extracted using the Machery-Nagel NucleoSpin Blood kit according to the manufacturer's instructions. DNA samples were relocated to the Australian Genome Research Facility (Melbourne, Australia) where bisulphite conversion and subsequent methylation quantification was conducted using the Illumina Methylation EPIC array platform according to the manufacturer's instructions.

Epigenome-wide DNAm was assessed using the Illumina Infinium MethylationEPIC BeadChip (Illumina, Inc., San Diego, CA, USA), which interrogates $>850,000$ CpGs associated with over 24,000 genes. A standard protocol was used to process arrays [33]. To control for batch effects, samples were randomly allocated on microarrays. The bead chips were scanned by a BeadStation. We used Bioconductor packages IMA [34] and ComBat [35] for processing the methylation data and removal of batch-effect, respectively. The methylation level ( $\beta$ value) was determined for each $C p G$ locus using the Methylation module of BeadStudio software. Beta values $\left(\beta=\frac{\text { methylated }}{\text { methylated }+ \text { unmethylated }+c}\right)$ indicate the proportions of methylated over the sum of methylated and unmethylated sites and $\mathrm{c}$ as a constant to prevent dividing by zero.

\subsection{Prior Data to Conduct Focused Analyses}

The Pregnancy and Childhood Epigenetics (PACE) consortium [29], in order to identify smoking-related $\mathrm{CpG}$, used a population of 13 cohorts from the US and Europe that, with the same reproducible platform, measured CpG-specific DNAm across the epigenome in newborns. DNA isolated from cord blood samples was processed with the Illumina Infinium HumanMethylation450 (450K) BeadChip (Illumina), resulting in 6685 newborns participating in this meta-analysis. First, CpGs identified to be related to maternal smoking 
are taken from this EWAS, as performed by Joubert et al. [29]. In a second step, for further focus, we used the IoW birth cohort [30] to test which of the smoking-related CpGs are also associated with birth weight. The IoW birth cohort was established in the United Kingdom to study the natural history of asthma and allergic conditions prospectively. Details on study design, enrolment, and follow-up procedures are described in detail elsewhere [30].

\subsection{Statistical Analysis}

Analyses were conducted using SAS ${ }^{\mathrm{TM}}$ software, Version 9.4 of the SAS System for Windows, and Stata software (StataCorp. 2017. Stata Statistical Software: Release 15. College Station, TX, USA). In the IoW birth cohort, potential associations of DNAm sites with birth weight were screened using the ttScreening R package (v1.5, http:// cran.rproject.org/web/packages/ttScreening/ (accessed on 1 February 2021)) [36]. This method removes non-informative $\mathrm{CpGs}$ in a course of 100 repetitions of a training-and-testing process with robust regressions. To estimate differential DNAm in the BLT cohort, we applied generalised linear models (GLM). A flow diagram of models and sample size is presented in Figure 1, showing the different steps in the analysis.

Focus on 568 cytosine-phosphate-guanine sites (CpGs) related to gestational smoking (Joubert et al. 2016).

Use the Isle of Wight Birth Cohort $(n=796)$ to test, which of the smoking related CpGs are also associated with birth weight

( 520 of 568 CpGs could be tested, 30 were identified to be related to birth weight).

Test whether the identified $30 \mathrm{CpG}$ are also associated with birth weight in a smaller subsample $(n=94)$ of the Breathing for Life Trial (BLT) randomised controlled trial (nine were associated).

Test whether these nine CpGs were related to gestational carbon-monoxide (CO) exposure and whether CpGs constitute a mediating variable between $\mathrm{CO}$ exposure and birth weight on the BLT subsample with CO-exposure $(n=84)$.

Figure 1. Flowchart of the analytical strategy identifying newborn DNA methylation sites that link gestational CO-exposure and offspring birth weight.

Chi-squared tests were performed to compare the distribution of demographic and obstetric descriptors among women with smoking and no smoking exposure during pregnancy. Models used confounders including maternal age, parity, and infant sex. To adjust for possible confounding in DNAm that might occur from cell composition in whole blood [37], we also selected seven cell types (lymphocytes TCD4 cells, lymphocytes TCD8 cells, Eosinophils, NK cells, neutrophils, B cells, and Monocytes) that were included as covariates in the linear regression. In the regression models, potential confounders were dropped from the full model, which includes all potential covariates one at a time, if the effects of interest in specific associations, i.e., CO-exposure and DNAm or DNAm and birth weight, did not change by more than $10 \%$ of the original values. DNAm sites were annotated based on data provided by Illumina. We applied the Bonferroni correction $(p<0.05 /$ (the number of CpGs analysed)), to account for multiple testing in EWAS results.

Path analysis or structural equation modelling (SEM) [38,39] were conducted to assess whether the association between gestational CO-exposure and offspring birth weight was mediated by cord blood DNAm. SEM was used to estimate direct, indirect (mediated), and total associations between maternal CO-exposure and offspring birth weight. To reduce the number of covariates, we investigated whether covariates such as blood cell counts confounded associations assessed in the path analysis. We started with a full model including all reasonable paths, and then we dropped covariates one at a time until 
a parsimonious model was reached. We evaluated the goodness of fit (the empirical model is not statistically significantly different from the conceptional model) using the following criteria: (1) $p>0.05$, (2) standardized root mean square residual $<0.08$, (3) adjusted goodness of fit $>0.95$, and (4) root mean square error of approximation $<0.05$. All analyses were performed using the Statistical Analysis System (SAS 9.4, Cary, NC, USA).

\section{Results}

A total of 94 participants were included in the analyses; $\mathrm{eCO}$ was assessed in all participants. Eleven self-reported that they smoked during pregnancy (mean age 29.2 \pm 5.2 ), and 83 self-reported not to have smoked during pregnancy (mean age $30 \pm 4.8$ ). Using an eCO level of $6 \mathrm{ppm}$ as recommended by Gomez et al. [40] as the reference point to validate smoking abstinence, eleven participants (approximately $12 \%$ ) had eCO levels greater than six ppm (Table 1). The mean eCO levels were $16.8 \pm 16.1 \mathrm{ppm}$ for self-reported smokers and $2.1 \pm 1.2 \mathrm{ppm}$ for self-reported non-smokers $(p<0.001)$ (Figure 2$)$.

Table 1. Characteristics of the participants for the association between umbilical cord blood DNAm and birth weight.

\begin{tabular}{|c|c|c|c|c|c|c|}
\hline & \multicolumn{3}{|c|}{ Self-Reported Smoking } & \multicolumn{3}{|c|}{$\mathrm{eCO}>6 \mathrm{ppm}$} \\
\hline & Yes $(n=11)$ & No $(n=83)$ & $p$-Value & Yes $(n=11)$ & No $(n=83)$ & $p$-Value \\
\hline Maternal age at childbirth, years (mean, SD) & $29.2(5.2)$ & $30.0(4.8)$ & 0.659 & $29.9(4.4)$ & $29.9(5.4)$ & 0.999 \\
\hline Parity, nulliparous (\%) & $27.3 \%$ & $54.9 \%$ & 0.085 & $27.3 \%$ & $54.9 \%$ & 0.085 \\
\hline Gestational age at birth, weeks (mean, SD) & $38.7(0.4)$ & $39.3(1.3)$ & 0.186 & $38.9(1.3)$ & $39.3(1.4)$ & 0.425 \\
\hline Infant sex, male $(\%)$ & $63.6 \%$ & $50.6 \%$ & 0.416 & $54.50 \%$ & $51.80 \%$ & 0.864 \\
\hline Birth weight, $(\mathrm{g})$ (mean, SD) & $3328(408.5)$ & $3537(487)$ & 0.178 & $3134(353)$ & $3563(475)$ & 0.005 \\
\hline Birth weight females (g) (mean, SD) & $3030(345)$ & $3452(445)$ & 0.074 & $3006(303.5)$ & 3465 (442) & 0.030 \\
\hline Birth weight males (g) (mean, SD) & $3499(354)$ & $3618(516)$ & 0.559 & $3240(381)$ & $3651(491)$ & 0.055 \\
\hline Socioeconomic Index for Areas (SEIFA), \% (mean, SD) & $4.1(1.6)$ & $4.9(1.6)$ & 0.139 & $4.3(1.5)$ & $4.9(1.6)$ & 0.276 \\
\hline Unemployment $(\%)$ & $72.7 \%$ & $30.0 \%$ & 0.005 & $63.6 \%$ & $31.3 \%$ & 0.035 \\
\hline Caesarean birth (\%) & $36.4 \%$ & $28.0 \%$ & 0.568 & $27.3 \%$ & $29.3 \%$ & 0.888 \\
\hline
\end{tabular}

The average difference in birth weight between self-reported smokers and nonsmokers was $209 \mathrm{~g}(p=0.18)$. Using the $\mathrm{eCO}(>6 \mathrm{ppm})$ to discriminate between smokers and non-smokers, the average difference in birth weight was $429 \mathrm{~g}(p=0.005)$. Infant sex differences were identified, such as higher birth weight among males. In female newborns, the average birth weight was $459 \mathrm{~g}$ lower in the $\mathrm{eCO} \leq 6 \mathrm{ppm}$ subgroup compared to $>6 \operatorname{ppm}(p=0.03$, Table 1$)$.

Among those with higher eCO levels ( $>6 \mathrm{ppm}$ ), $81.8 \%$ of the mothers reported smoking (Sensitivity), whereas among those with lower eCO levels $97.6 \%$ stated no smoking (Specificity, Table 2). The agreement between self-reported smoking status and measurable CO levels was substantial $($ kappa $=0.79)($ Table 2$)$. However, two reportedly non-smoking participants had eCO levels higher than the reference point, and two reportedly smoking participants had eCO levels $\leq 6 \mathrm{ppm}$.

Table 2. Agreement between self-reported smoking and measurable eCO.

\begin{tabular}{cccccc}
\hline & \multicolumn{2}{c}{ eCO $>\mathbf{6} \mathbf{~ p p m}$} & \multicolumn{2}{c}{ eCO $\leq \mathbf{6} \mathbf{~ p p m}$} & Kappa \\
\hline & No. & $\%$ & No. & $\%$ & \\
Self-reported smoking & 9 & 81.8 & 2 & 2.4 & 0.79 \\
No self-reported smoking & 2 & 18.2 & 81 & 97.6 & \\
\hline
\end{tabular}




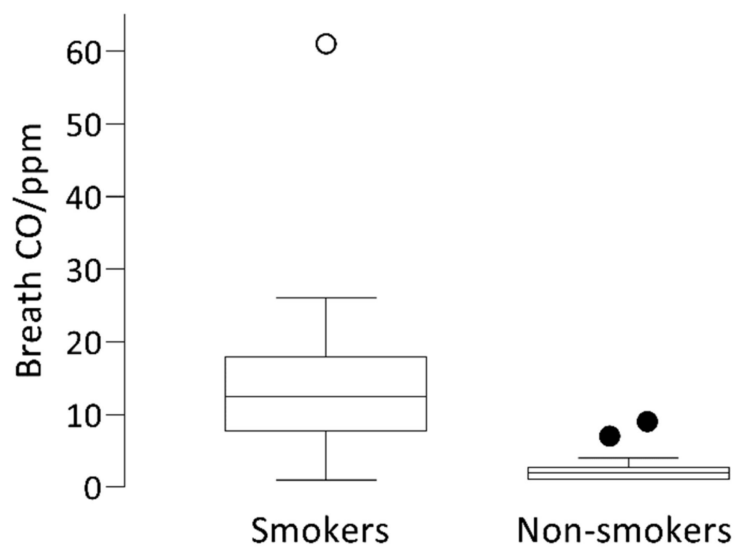

Figure 2. CO concentration in exhaled air in self-reported smokers $(n=11)$, and self-reported non-smokers $(n=83)$.

Of 568 DNAm sites related to gestational smoking described by Joubert et al. [29], 520 could be tested. We used the IoW birth cohort to reduce the number of potential smoking related DNAm sites to those that also were associated with birth weight. Of the screened $520 \mathrm{CpG}$ site, 30 were identified to be related to birth weight. The methylation is expressed as beta values ranging between 0 and 1 ; multiplied by 100 , this indicates the percent of methylation of a CpG. Then, in the BLT cohort, nine of these $30 \mathrm{CpGs}$ were significantly associated with birth weight (Table 3), adjusted for maternal age, parity, and infant sex. Their effects on birth weight are expressed per percentage of methylation.

Table 3. Methylation of specific cytosine by guanines (CpGs) from cord blood DNA associated with birth weight in the Breathing for Life Trial (BLT) subsample after Bonferroni correction for multiple testing.

\begin{tabular}{|c|c|c|c|c|c|}
\hline CpG & Gene & Chromosome & $\begin{array}{c}\text { Effect on Birth Weight in Gram per Percent } \\
\text { Methylation } i\end{array}$ & $\begin{array}{l}\text { Standard Error (SE) of the Birth } \\
\text { Weight Effect }\end{array}$ & $p$-Value \\
\hline cg27434149 & $A N K 3$ * & 10 & -32.24 & 7.76 & $<0.0001$ \\
\hline cg02264407 & LMO7 & 13 & 49.13 & 13.37 & 0.0004 \\
\hline cg18444875 & OXR1 & 8 & -31.47 & 8.59 & 0.0004 \\
\hline cg22057874 & OSBPL6 & 2 & -55.21 & 18.35 & 0.0034 \\
\hline cg22902505 & PRDM8 & 4 & 15.41 & 5.18 & 0.0038 \\
\hline cg06012804 & HES1 * & 3 & 29.28 & 12.69 & 0.0235 \\
\hline cg00169122 & ANKRD11 & 16 & -35.11 & 15.47 & 0.0257 \\
\hline cg07810039 & TGFB2 & 1 & -18.56 & 8.45 & 0.0308 \\
\hline cg09726279 & $M Y B B P 1 A$ & 17 & 74.06 & 34.36 & 0.0339 \\
\hline cg00624799 & ZNF710 & 15 & 25.11 & 12.8 & 0.0529 \\
\hline cg07340025 & $A N K H^{*}$ & 5 & -19.52 & 9.99 & 0.0541 \\
\hline cg12374579 & ASPSCR1 & 17 & 28.74 & 14.81 & 0.0555 \\
\hline cg18183624 & $I G F 2 B P 1$ & 17 & 17.43 & 9.52 & 0.0707 \\
\hline cg04872675 & TMEM119 * & 12 & 20.54 & 11.43 & 0.0759 \\
\hline cg12160087 & CCDC64 & 12 & 33.03 & 19.18 & 0.0886 \\
\hline cg25311470 & NRCAM & 7 & 45.57 & 28.11 & 0.1087 \\
\hline cg11043990 & RNF157 & 17 & -62.65 & 38.81 & 0.1102 \\
\hline cg00376553 & TSC22D4 & 7 & 20.25 & 13.38 & 0.1337 \\
\hline cg23928512 & ASPSCR1 & 17 & 19.44 & 12.94 & 0.1366 \\
\hline cg07638500 & MYLK & 3 & 16.40 & 12.55 & 0.1947 \\
\hline cg01668281 & CLDN14 & 21 & 24.92 & 19.94 & 0.2148 \\
\hline cg18561976 & ICOS & $\begin{array}{c}21 \\
2\end{array}$ & 13.04 & 12.16 & 0.2867 \\
\hline cg14001239 & SVIL & 10 & 11.2 & 11.19 & 0.3198 \\
\hline cg24513387 & LOC $286083 *$ & 8 & 22.94 & 23.01 & 0.3214 \\
\hline cg02973307 & KCTD15 & 19 & 9.85 & 11.19 & 0.3813 \\
\hline cg13784312 & RAPGEF1 & 9 & -8.39 & 9.58 & 0.3835 \\
\hline cg02227813 & SAMD3 & 6 & -13.42 & 17.83 & 0.4538 \\
\hline cg07466788 & SLC16A3 & 17 & 18.07 & 25.79 & 0.4853 \\
\hline cg26208507 & CCND2 * & 12 & -6.93 & 12.86 & 0.5913 \\
\hline cg21611682 & LRP5 & 11 & 0.62 & 23.13 & 0.9979 \\
\hline
\end{tabular}

${ }^{*}$ Nearest gene. ${ }^{i}$ Positive $\beta$ difference indicates higher methylation and negative $\beta$ lower methylation.

Focusing on the nine CpGs significantly associated with birth weight, we then tested whether self-reported smoking or exhaled CO measurements were linked with these CpGs. Only one $\mathrm{CpG}$ in the body of the $\mathrm{LMO} 7$ gene showed a significant association with eCO levels, and none were associated with self-reported maternal smoking (Table 4). 
Table 4. Differential methylation in cord blood DNA in the BLT population associated with maternal smoking exposure during pregnancy.

\begin{tabular}{cccccccccc}
\hline & & \multicolumn{4}{c}{ Self-Reporting Smoking } & \multicolumn{2}{c}{ eCO } \\
\hline Gene & Gene Group & Chr & CpG & Coef & SE & $p$-Value & Coef & SE & $p$-Value \\
\hline ANK3 P ${ }^{+}$ & & 10 & cg27434149 & 0.023 & 0.020 & 0.246 & 0.036 & 0.020 & 0.081 \\
LMO7 & Body & 13 & cg02264407 & -0.020 & 0.011 & 0.077 & -0.023 & 0.011 \\
OXR1 & Body & 8 & cg18444875 & 0.023 & 0.017 & 0.177 & 0.030 & 0.017 & 0.041 \\
OSBPL6 & TSS200; Body & 2 & cg22057874 & 0.009 & 0.007 & 0.229 & 0.011 & 0.007 & 0.148 \\
PRDM8 & 5'UTR; 5'UTR $^{\prime}$ & 4 & cg22902505 & -0.003 & 0.034 & 0.933 & -0.033 & 0.035 \\
HES1 P + & & 3 & cg06012804 & 0.010 & 0.010 & 0.297 & 0.006 & 0.010 \\
ANKRD11 & 5'UTR & 16 & cg00169122 & -0.001 & 0.011 & 0.944 & 0.013 & 0.012 & 0.547 \\
TGFB2 & Body; Body & 1 & cg07810039 & 0.020 & 0.015 & 0.202 & 0.018 & 0.016 & 0.263 \\
MYBBP1A & Body; Body & 17 & cg09726279 & -0.007 & 0.005 & 0.141 & -0.007 & 0.005 & 0.187 \\
\hline
\end{tabular}

${ }^{+}$Nearest gene.

To further test whether this CpG site mediates the effect of smoking on birth weight, we conducted structural equation analyses (path analyses). Essential confounders were infant sex and the proportion of B cells, CD4 cells, and eosinophils in cord blood. Methylation at cg02264407 in the LMO7 gene showed a mediating role between exhaled $\mathrm{CO}$ and birth weight (Table 5), controlling for confounders (Figure 3). CD4 ${ }^{+} \mathrm{T}$ cells, B cells, and eosinophils needed to be adjusted for, since the proportion of these cells also affected the methylation of cg02264407. Figure 3 shows a direct effect of $\mathrm{CO}$-exposure on birth weight and an indirect effect of CO-exposure on birth weight via the $\mathrm{CpG}$ site cg02264407. LMO7 methylation difference was most pronounced in $\mathrm{CD}^{+} \mathrm{T}$ cells negatively affecting its proportion in whole blood. Exposure to $\mathrm{CO}$ was associated with a $2.3 \%$ decrease in infant DNAm at the $\operatorname{cg} 02264407(p=0.035)$. The average methylation at this site is $39 \%$. For ease of interpretation and estimation, the effect of DNAm on birth weight on the path diagram is represented as the percentage methylation value $(\beta \times 100)$. For each $1 \%$ increase in methylation at this site, the birth weight increased by $44.8 \mathrm{~g}(p<0.001)$. In other words, a $1 \%$ reduction of methylation of cg0226440 by eCO also resulted in a reduction of birth weight by $44.8 \mathrm{~g}$.

Table 5. Analytical path model showing the unstandardised coefficients for the associations of DNAm at the cg02264407 and CO-exposure with infant birth weight and $p$ values (in parentheses).

\begin{tabular}{|c|c|c|c|c|c|c|}
\hline & $\operatorname{cg} 02264407$ & $\begin{array}{l}\text { Exhaled Carbon Monoxide } \\
\quad(\mathrm{eCO})>6 \mathrm{ppm}\end{array}$ & Gender & B Cells & $\mathrm{CD}^{+} \mathrm{T}^{\mathrm{T}}$ Cells & Eosinophils \\
\hline \multicolumn{7}{|l|}{ Birth weight } \\
\hline Direct & $4476(<0.001)$ & $-368.07(0.02)$ & $-134.48(0.16)$ & - & $-388.66(0.67)$ & - \\
\hline Indirect & - & $-103.25(0.04)$ & - & $678.4(0.32)$ & $-1791(0.0003)$ & $-586.33(0.33)$ \\
\hline $\begin{array}{c}\text { Total } \\
\operatorname{cg} 02264407\end{array}$ & $4476(<0.001)$ & $-471.32(0.003)$ & $-134.48(0.16)$ & $678.4(0.32)$ & $-2180(0.08)$ & $-586.33(0.33)$ \\
\hline Direct & - & $-0.023(0.035)$ & - & $0.15(0.32)$ & $-0.40(<0.0001)$ & $-0.13(0.32)$ \\
\hline Indirect & - & - & - & - & - & - \\
\hline Total & - & $-0.023(0.035)$ & - & $0.15(0.32)$ & $-0.40(<0.0001)$ & $-0.13(0.32)$ \\
\hline
\end{tabular}




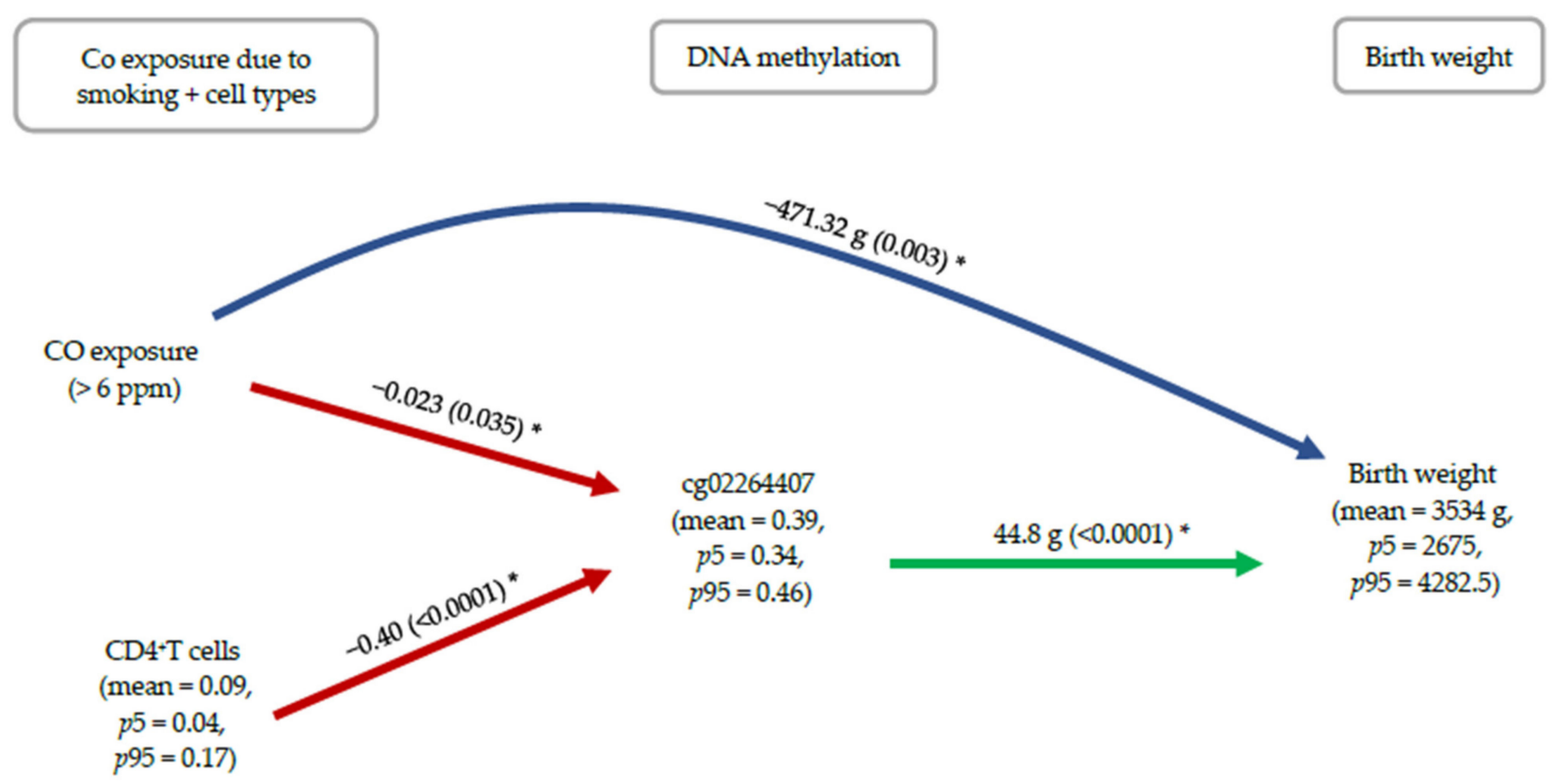

CO exposure + cell types $\rightarrow$ DNA methylation

DNA methylation $\rightarrow$ Birth weight

CO exposure $\rightarrow$ Birth weight

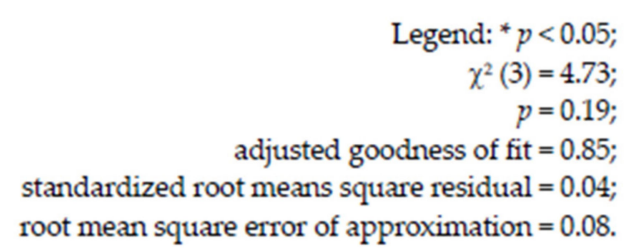

$\chi^{2}(3)=4.73$

$p=0.19$;

Figure 3. Path diagram - results from the structural equation model. Controlled for CO-exposure, $\mathrm{CD} 4^{+} \mathrm{T}$ cells, Eosinophils, $\mathrm{B}$ cells and gender. The effect of DNAm on birth weight in the path diagram is represented as the percentage methylation value $(\beta \times 100)$.

\section{Discussion}

We measured variation in cord blood DNAm in 94 infants born to mothers with asthma. Using secondary analysis, an analysis focusing on 520 smoking related CpGs sites was used to identify that $\mathrm{CpGs}$ also associated with birth weight. We discovered $30 \mathrm{CpGs}$. Then, in the BLT cohort, we tested whether self-reported smoking status during pregnancy, and/or $\mathrm{CO}$ exhalation as a biomarker of current cigarette exposure, are statistically significantly associated with any of these 30 DNAm sites. We found nine CpGs sites (on nine genes), after Bonferroni correction, to be significantly associated with birth weight. Focusing on the effects of maternal smoking, the methylation of $\operatorname{cg} 02264407$ on the LMO7 gene was significantly linked with exhaled CO measurements. Interestingly, none of the CpGs was associated with self-reported smoking. Finally, path analyses showed a direct effect of CO-exposure and an indirect effect of CO-exposure on birth weight via the $\mathrm{CpG}$ site $\operatorname{cg} 02264407$ on the $L M O 7$ gene. These results add to the developing literature demonstrating that maternal smoking during pregnancy can influence epigenetic modifications in early fetal/infant development $[22,29,41,42]$, providing a likely mechanism linking them to altered gene function and perinatal health outcomes.

Assessing an epigenetic role in disease pathogenesis is of interest when investigating physical development in early childhood [22,43], in particular when related to early life exposure from tobacco smoke [44]. Gene expression modulation can be regulated by an epigenetic mechanism, including changes in DNAm, thus affecting fetal growth, and contributing to chronic disease development in later life. The influence of intrauterine exposure of tobacco smoke and their epigenetic changes have been reported for cord blood samples [45,46] but also later in childhood [29] and adulthood [47] demonstrating the 
impacts of maternal smoking during pregnancy on the offspring when DNAm persists independently of active smoking. Surprisingly, none of the CpGs in our sample were associated with self-reported smoking status; however, one $\mathrm{CpG}$ was significantly linked with exhaled $\mathrm{CO}$ measurements. Thus reporting bias (women may not reveal their smoking status during pregnancy) can affect the assessment of smoking, particular in a small sample [48]. Unbiased eCO measurement helped to detect significantly differently DNAm. Hence, to avoid a social desirability bias we decided to progress the analyses using the $\mathrm{eCO}$ as a measure of exposure [49]. The half-life of carbon monoxide ranges from five to six hours, and its elimination is related to minute ventilation, the full length of carbon monoxide exposure and the percentage of inspired oxygen [50]. This may explain why two participants who self-reported as smoking during pregnancy had eCO level lower than six ppm.

Figure 3 shows a direct effect of eCO on birth weight and an indirect effect via DNAm. Supporting pregnant women to quit smoking during pregnancy is the most significant intervention that can be established to decrease the risk of adverse birth outcomes; however, since there is an indirect effect, we may mitigate the negative effect on birth weight by blocking the indirect path. For instance, to deal with the adverse effect of maternal smoking, a recent study suggests that daily supplementation with vitamin $C$ administered to pregnant women who continue to smoke tobacco may restore the effects of smokingrelated changes caused for specific CpGs [51]. In addition, dietary interventions in adults have been shown to potentially improve DNAm changes caused by smoking exposures [52] This could be an indication of a possible mechanism of intervening to reduce exposure effects after the exposure has already taken place, such as reinforcing the benefit of exclusive breastfeeding or potential dietary supplementation in offspring born to mothers who would not quit smoking during pregnancy [53-56]. However, more research is needed.

Our results are consistent with the hypothesis that tobacco smoke exposure in utero exerts direct biological influence on the developing infant through altering methylation of specific $\mathrm{CpGs}$, in particular at $L M O 7$, in turn affecting birth weight. Differential methylation of this gene related to maternal smoking was also observed in other EWAS in cord blood [57] and another study characterising smoking and methylation in adults [58]; however, it was not consistently replicated. LMO7 is a multifunctional protein that can be found in several sites, mostly in the nucleus, plasm membrane, and at epithelial adherence junctions. Besides, it is broadly expressed in skeletal muscle and heart, with increased levels of expression in the lung [59-61]. Investigating the physio-pathological relevance of $L M O 7$, gene ontology annotations reported connections between the LMO7 gene and the biological process of regulation of cell adhesion (GO:0030155) and regulation of signalling (GO:0023051). A Reactome pathway [62] analysis showed significant upregulation of two pathways for Class I MHC mediated antigen processing \& presentation $(p<0.05)$ and neddylation $(p<0.05)$. Albeit the latter hypothesis is controversial [63], deletion of the $L M O 7$ gene in mice resulted in an increased postnatal lethality due to a dramatic growth abnormality [64]. Moreover, it was reported to be imperative for appropriate skeletal muscle differentiation [65]. Despite these findings, the role of LMO7 in human development has yet to be studied.

The small sample size of 94 pregnant mothers and their offspring is a limitation. Hence, we tried to focus on a limited number of DNAm sites that were detected in prior studies related to gestational smoking. Nevertheless, it is likely that other CpGs related to maternal smoking and offspring birth weight were not detected due to the reduced statistical power. In the present work, a potential limitation was that eCO measurements were not performed throughout pregnancy. The eCO measurement depended on the randomisation to the control or the intervention arm, which dictated a different regime of study visits. Consequently, we used only the baseline eCO measurement for both arms, it being unfeasible to use the data from attendance at other visits. A previous study indicated that differential methylation at some CpGs related to maternal smoking seems to require a sustained exposure to observe the effects on DNAm at birth [57]. Despite this limitation 
and the small sample size, we observed significant differences for the selected CpG and related $\mathrm{CD} 4^{+}$cells.

Strengths of our study include more objective measurement of $\mathrm{CO}$ as a marker of maternal smoking. Nevertheless, to avoid false-negative CO assessments, future studies should increase the density of $\mathrm{CO}$ measurement, since $\mathrm{CO}$ has a short half-life of fivesix hours resulting in lower or non-detectable CO-levels in some participants. A second strength is the use of cord blood samples to assess DNAm as a likely mediator of adverse effects of in utero exposure to tobacco smoking on offspring birth weight without confounding from any post-birth exposures. Thirdly, even though we could only include participants for whom cord blood samples were available, the mode of delivery was not limited to vaginal birth. Thus, it is unlikely that only relatively healthier infants were included, excluding the possibility of underestimating the effects of smoking exposure during pregnancy. Fourthly, we compared associations of smoking related CpG sites with active tobacco use information collected through a self-administered questionnaire and eCO. The usual practice of analysing multiple exposures concurrently can lead to errors in explanation, as it is possible that the multicollinearity of exposures biases their assessment.

\section{Conclusions}

This is the first study to show that measurement of eCO between the 12th and 22nd week of pregnancy had inverse association with cord blood methylation of cg02264407 on the LMO7 gene. In turn, a reduction of the methylation of cg02264407 was associated with lower birth weight. Our results are consistent with previous findings and demonstrate a potential epigenetic mediating effect with the consequence of in utero tobacco smoke exposure affecting fetal growth, showing a specific pathway via reducing the methylation of LMO7. Additional investigations to confirm these findings are recommended due to limited sample size. Finally, emerging approaches such as diet intervention hold the potential to prevent indirect adverse effect of maternal smoking on birth weight in vulnerable populations.

Author Contributions: Conceptualization, A.C., W.K., J.M. and E.D.Q.A.; funding acquisition, A.C., J.M., V.E.M., P.G.; methodology, W.K.; formal analysis, E.D.Q.A. and W.K.; investigation, E.D.Q.A., G.M.C.G. and J.G.; writing-original draft preparation, E.D.Q.A.; writing—review and editing, E.D.Q.A., W.K., J.M., A.C., V.E.M., P.G. and G.M.C.G. All authors have read and agreed to the published version of the manuscript.

Funding: This research was funded by the National Health and Medical Research Council of Australia (NHMRC, grant ID: 455593, 1060983) and Hunter Children's Research Foundation.

Institutional Review Board Statement: The study was conducted according to the guidelines of the Declaration of Helsinki, and approved by Hunter New England Human Research Ethics Committee (Reference Number 12/10/17/3.04, NSW HREC Reference No: HREC/12/ HNE/357).

Informed Consent Statement: Informed consent was obtained from all subjects involved in the study.

Data Availability Statement: The data presented in this study is available upon request to the corresponding author.

Acknowledgments: The authors would like to thank the midwives of the antenatal clinics and research staff who assisted with recruitment of mothers.

Conflicts of Interest: The authors declare no conflict of interest.

\section{References}

1. Li, H.; Hansen, A.R.; McGalliard, Z.; Gover, L.; Yan, F.; Zhang, J. Trends in Smoking and Smoking Cessation during Pregnancy from 1985 to 2014, Racial and Ethnic Disparity Observed from Multiple National Surveys. Matern. Child Health J. 2018, 22, 685-693. [CrossRef]

2. McEvoy, C.T.; Spindel, E.R. Pulmonary Effects of Maternal Smoking on the Fetus and Child: Effects on Lung Development, Respiratory Morbidities, and Life Long Lung Health. Paediatr. Respir. Rev. 2017, 21, 27-33. [CrossRef] [PubMed] 
3. Lange, S.; Probst, C.; Rehm, J.; Popova, S. National, regional, and global prevalence of smoking during pregnancy in the general population: A systematic review and meta-analysis. Lancet Glob. Health 2018, 6, e769-e776. [CrossRef]

4. De Queiroz Andrade, E.; Da Silva Sena, C.R.; Collison, A.; Murphy, V.E.; Gould, G.S.; Bonevski, B.; Mattes, J. Association between active tobacco use during pregnancy and infant respiratory health: A systematic review and meta-analysis. BMJ Open 2020, 10, e037819. [CrossRef]

5. Shah, N.R.; Bracken, M.B. A systematic review and meta-analysis of prospective studies on the association between maternal cigarette smoking and preterm delivery. Am. J. Obs. Gynecol. 2000, 182, 465-472. [CrossRef]

6. Flenady, V.; Koopmans, L.; Middleton, P.; Frøen, J.F.; Smith, G.C.; Gibbons, K.; Coory, M.; Gordon, A.; Ellwood, D.; McIntyre, H.D.; et al. Major risk factors for stillbirth in high-income countries: A systematic review and meta-analysis. Lancet 2011, 377, 1331-1340. [CrossRef]

7. Hackshaw, A.; Rodeck, C.; Boniface, S. Maternal smoking in pregnancy and birth defects: A systematic review based on 173,687 malformed cases and 11.7 million controls. Hum. Reprod. Update 2011, 17, 589-604. [CrossRef] [PubMed]

8. National Center for Chronic Disease Prevention; Health Promotion Office on Smoking and Health. Reports of the Surgeon General. In The Health Consequences of Smoking - 50 Years of Progress: A Report of the Surgeon General; Centers for Disease Control and Prevention (US): Atlanta, GA, USA, 2014.

9. Alexander, B.T.; Dasinger, J.H.; Intapad, S. Fetal programming and cardiovascular pathology. Compr. Physiol. 2015, 5, 997-1025. [CrossRef] [PubMed]

10. Knopik, V.S.; Maccani, M.A.; Francazio, S.; McGeary, J.E. The epigenetics of maternal cigarette smoking during pregnancy and effects on child development. Dev. Psychopathol. 2012, 24, 1377-1390. [CrossRef]

11. Rayfield, S.; Plugge, E. Systematic review and meta-analysis of the association between maternal smoking in pregnancy and childhood overweight and obesity. J. Epidemiol. Community Health 2017, 71, 162-173. [CrossRef] [PubMed]

12. Asmare, G.; Berhan, N.; Berhanu, M.; Alebel, A. Determinants of low birth weight among neonates born in Amhara Regional State Referral Hospitals of Ethiopia: Unmatched case control study. BMC Res. Notes 2018, 11, 447. [CrossRef]

13. Xu, X.F.; Li, Y.J.; Sheng, Y.J.; Liu, J.L.; Tang, L.F.; Chen, Z.M. Effect of low birth weight on childhood asthma: A meta-analysis. BMC Pediatr. 2014, 14, 275. [CrossRef]

14. Flaherman, V.; Rutherford, G.W. A meta-analysis of the effect of high weight on asthma. Arch. Dis. Child. 2006, 91, 334-339. [CrossRef]

15. Palatianou, M.E.; Simos, Y.V.; Andronikou, S.K.; Kiortsis, D.N. Long-term metabolic effects of high birth weight: A critical review of the literature. Horm. Metab. Res. 2014, 46, 911-920. [CrossRef] [PubMed]

16. Hanson, M.A.; Gluckman, P.D. Early Developmental Conditioning of Later Health and Disease: Physiology or Pathophysiology? Physiol. Rev. 2014, 94, 1027-1076. [CrossRef]

17. Barker, D.J.; Winter, P.D.; Osmond, C.; Margetts, B.; Simmonds, S.J. Weight in infancy and death from ischaemic heart disease. Lancet 1989, 2, 577-580. [CrossRef]

18. Barker, D.J.; Osmond, C. Infant mortality, childhood nutrition, and ischaemic heart disease in England and Wales. Lancet 1986, 1, 1077-1081. [CrossRef]

19. Barker, D.J.; Gluckman, P.D.; Godfrey, K.M.; Harding, J.E.; Owens, J.A.; Robinson, J.S. Fetal nutrition and cardiovascular disease in adult life. Lancet 1993, 341, 938-941. [CrossRef]

20. Barker, D.J. In utero programming of chronic disease. Clin. Sci. 1998, 95, 115-128. [CrossRef]

21. Kwon, E.J.; Kim, Y.J. What is fetal programming?: A lifetime health is under the control of in utero health. Obs. Gynecol. Sci. 2017, 60, 506-519. [CrossRef] [PubMed]

22. Küpers, L.K.; Monnereau, C.; Sharp, G.C.; Yousefi, P.; Salas, L.A.; Ghantous, A.; Page, C.M.; Reese, S.E.; Wilcox, A.J.; Czamara, D.; et al. Meta-analysis of epigenome-wide association studies in neonates reveals widespread differential DNA methylation associated with birthweight. Nat. Commun. 2019, 10, 1893. [CrossRef]

23. Lim, D.H.; Maher, E.R. DNA methylation: A form of epigenetic control of gene expression. Obs. Gynaecol. 2010, 12, 37-42. [CrossRef]

24. Suter, M.; Ma, J.; Harris, A.S.; Patterson, L.; Brown, K.A.; Shope, C.; Showalter, L.; Abramovici, A.; Aagaard-Tillery, K.M. Maternal tobacco use modestly alters correlated epigenome-wide placental DNA methylation and gene expression. Epigenetics 2011, 6, 1284-1294. [CrossRef]

25. Zhu, L.Y.; Zhu, Y.R.; Dai, D.J.; Wang, X.; Jin, H.C. Epigenetic regulation of alternative splicing. Am. J. Cancer Res. 2018, 8, 2346-2358.

26. Küpers, L.K.; Xu, X.; Jankipersadsing, S.A.; Vaez, A.; la Bastide-van Gemert, S.; Scholtens, S.; Nolte, I.M.; Richmond, R.C.; Relton, C.L.; Felix, J.F.; et al. DNA methylation mediates the effect of maternal smoking during pregnancy on birthweight of the offspring. Int. J. Epidemiol. 2015, 44, 1224-1237. [CrossRef] [PubMed]

27. Witt, S.H.; Frank, J.; Gilles, M.; Lang, M.; Treutlein, J.; Streit, F.; Wolf, I.A.C.; Peus, V.; Scharnholz, B.; Send, T.S.; et al. Impact on birth weight of maternal smoking throughout pregnancy mediated by DNA methylation. BMC Genom. 2018, 19, 290. [CrossRef]

28. Gorber, S.C.; Schofield-Hurwitz, S.; Hardt, J.; Levasseur, G.; Tremblay, M. The accuracy of self-reported smoking: A systematic review of the relationship between self-reported and cotinine-assessed smoking status. Nicotine Tob. Res. 2009, 11, 12-24. [CrossRef] 
29. Joubert, B.R.; Felix, J.F.; Yousefi, P.; Bakulski, K.M.; Just, A.C.; Breton, C.; Reese, S.E.; Markunas, C.A.; Richmond, R.C.; Xu, C.J.; et al. DNA Methylation in Newborns and Maternal Smoking in Pregnancy: Genome-wide Consortium Meta-analysis. Am. J. Hum. Genet. 2016, 98, 680-696. [CrossRef] [PubMed]

30. Arshad, S.H.; Holloway, J.W.; Karmaus, W.; Zhang, H.; Ewart, S.; Mansfield, L.; Matthews, S.; Hodgekiss, C.; Roberts, G.; Kurukulaaratchy, R. Cohort Profile: The Isle of Wight Whole Population Birth Cohort (IOWBC). Int. J. Epidemiol. 2018. [CrossRef] [PubMed]

31. Murphy, V.E.; Jensen, M.E.; Mattes, J.; Hensley, M.J.; Giles, W.B.; Peek, M.J.; Bisits, A.; Callaway, L.K.; McCaffery, K.; Barrett, H.L.; et al. The Breathing for Life Trial: A randomised controlled trial of fractional exhaled nitric oxide (FENO)-based management of asthma during pregnancy and its impact on perinatal outcomes and infant and childhood respiratory health. BMC Pregnancy Childbirth 2016, 16, 111. [CrossRef]

32. Australian Bureau of Statistics. Table 3 Postal Area (POA) Index of Relative Socio-economic Advantage and Disadvantage, 2016. In 2033.0.55.001-Census of Population and Housing: Socio-Economic Indexes for Areas (SEIFA), Australia, 2016; Australian Bureau of Statistics: Canberra, Australia, 2018.

33. Bibikova, M.; Fan, J.B. GoldenGate assay for DNA methylation profiling. Methods Mol. Biol. 2009, 507, 149-163. [CrossRef] [PubMed]

34. Wang, D.; Yan, L.; Hu, Q.; Sucheston, L.E.; Higgins, M.J.; Ambrosone, C.B.; Johnson, C.S.; Smiraglia, D.J.; Liu, S. IMA: An R package for high-throughput analysis of Illumina's 450K Infinium methylation data. Bioinformatics 2012, 28, 729-730. [CrossRef]

35. Johnson, W.E.; Li, C.; Rabinovic, A. Adjusting batch effects in microarray expression data using empirical Bayes methods. Biostatistics 2007, 8, 118-127. [CrossRef] [PubMed]

36. Ray, M.A.; Tong, X.; Lockett, G.A.; Zhang, H.; Karmaus, W.J. An Efficient Approach to Screening Epigenome-Wide Data. Biomed. Res. Int. 2016, 2016, 2615348. [CrossRef]

37. Reinius, L.E.; Acevedo, N.; Joerink, M.; Pershagen, G.; Dahlén, S.-E.; Greco, D.; Söderhäll, C.; Scheynius, A.; Kere, J. Differential DNA Methylation in Purified Human Blood Cells: Implications for Cell Lineage and Studies on Disease Susceptibility. PLoS ONE 2012, 7, e41361. [CrossRef]

38. O'Rourke, N.; Hatcher, L. A Step-by-Step Approach to Using SAS for Factor Analysis and Structural Equation Modeling, 2nd ed.; SAS Press: Cary, NC, USA, 2013.

39. Loehlin, J.C. Latent Variable Models: An Introduction to Factor, Path, and Structural Equation Analysis; Lawrence Erlbaum Associates: Mahwah, NJ, USA, 2004.

40. Gomez, C.; Berlin, I.; Marquis, P.; Delcroix, M. Expired air carbon monoxide concentration in mothers and their spouses above 5 ppm is associated with decreased fetal growth. Prev. Med. 2005, 40, 10-15. [CrossRef]

41. Gruzieva, O.; Merid, S.K.; Chen, S.; Mukherjee, N.; Hedman, A.M.; Almqvist, C.; Andolf, E.; Jiang, Y.; Kere, J.; Scheynius, A.; et al. DNA Methylation Trajectories During Pregnancy. Epigenet. Insights 2019, 12. [CrossRef] [PubMed]

42. Xu, C.-J.; Bonder, M.J.; Söderhäll, C.; Bustamante, M.; Baïz, N.; Gehring, U.; Jankipersadsing, S.A.; van der Vlies, P.; van Diemen, C.C.; van Rijkom, B.; et al. The emerging landscape of dynamic DNA methylation in early childhood. BMC Genom. 2017, 18, 25. [CrossRef]

43. Cutfield, W.S.; Hofman, P.L.; Mitchell, M.; Morison, I.M. Could Epigenetics Play a Role in the Developmental Origins of Health and Disease? Pediatric Res. 2007, 61, 68-75. [CrossRef]

44. Wu, C.-C.; Hsu, T.-Y.; Chang, J.-C.; Ou, C.-Y.; Kuo, H.-C.; Liu, C.-A.; Wang, C.-L.; Chuang, H.; Chen, C.-P.; Yang, K.D. Paternal Tobacco Smoke Correlated to Offspring Asthma and Prenatal Epigenetic Programming. Front. Genet. 2019, 10. [CrossRef]

45. Markunas, C.A.; Xu, Z.; Harlid, S.; Wade, P.A.; Lie, R.T.; Taylor, J.A.; Wilcox, A.J. Identification of DNA methylation changes in newborns related to maternal smoking during pregnancy. Environ. Health Perspect. 2014, 122, 1147-1153. [CrossRef]

46. Joubert, B.R.; Håberg, S.E.; Nilsen, R.M.; Wang, X.; Vollset, S.E.; Murphy, S.K.; Huang, Z.; Hoyo, C.; Midttun, Ø.; Cupul-Uicab, L.A.; et al. 450K epigenome-wide scan identifies differential DNA methylation in newborns related to maternal smoking during pregnancy. Environ. Health Perspect. 2012, 120, 1425-1431. [CrossRef] [PubMed]

47. Tehranifar, P.; Wu, H.-C.; McDonald, J.A.; Jasmine, F.; Santella, R.M.; Gurvich, I.; Flom, J.D.; Terry, M.B. Maternal cigarette smoking during pregnancy and offspring DNA methylation in midlife. Epigenetics 2018, 13, 129-134. [CrossRef] [PubMed]

48. Lavrakas, P.J. Encyclopedia of Survey Research Methods; Sage Publications, Inc.: Thousand Oaks, CA, USA, 2008. [CrossRef]

49. Althubaiti, A. Information bias in health research: Definition, pitfalls, and adjustment methods. J. Multidiscip. Healthc. 2016, 9 , 211-217. [CrossRef] [PubMed]

50. Pan, K.-T.; Leonardi, G.S.; Croxford, B. Factors Contributing to CO Uptake and Elimination in the Body: A Critical Review. Int. J. Environ. Res. Public Health 2020, 17, 528. [CrossRef] [PubMed]

51. Shorey-Kendrick, L.E.; McEvoy, C.T.; Ferguson, B.; Burchard, J.; Park, B.S.; Gao, L.; Vuylsteke, B.H.; Milner, K.F.; Morris, C.D.; Spindel, E.R. Vitamin C Prevents Offspring DNA Methylation Changes Associated with Maternal Smoking in Pregnancy. Am. J. Respir. Crit. Care 2017, 196, 745-755. [CrossRef]

52. Stidley, C.A.; Picchi, M.A.; Leng, S.; Willink, R.; Crowell, R.E.; Flores, K.G.; Kang, H.; Byers, T.; Gilliland, F.D.; Belinsky, S.A. Multivitamins, Folate, and Green Vegetables Protect against Gene Promoter Methylation in the Aerodigestive Tract of Smokers. Cancer Res. 2010, 70, 568-574. [CrossRef]

53. Hartwig, F.P.; Loret de Mola, C.; Davies, N.M.; Victora, C.G.; Relton, C.L. Breastfeeding effects on DNA methylation in the offspring: A systematic literature review. PLoS ONE 2017, 12, e0173070. [CrossRef] 
54. Sherwood, W.B.; Bion, V.; Lockett, G.A.; Ziyab, A.H.; Soto-Ramírez, N.; Mukherjee, N.; Kurukulaaratchy, R.J.; Ewart, S.; Zhang, H.; Arshad, S.H.; et al. Duration of breastfeeding is associated with leptin (LEP) DNA methylation profiles and BMI in 10-year-old children. Clin. Epigenet. 2019, 11, 1-10. [CrossRef]

55. Sae-Lee, C.; Corsi, S.; Barrow, T.M.; Kuhnle, G.G.C.; Bollati, V.; Mathers, J.C.; Byun, H.M. Dietary Intervention Modifies DNA Methylation Age Assessed by the Epigenetic Clock. Mol. Nutr. Food Res. 2018, 62, e1800092. [CrossRef]

56. Corley, J.; Cox, S.R.; Harris, S.E.; Hernandez, M.V.; Maniega, S.M.; Bastin, M.E.; Wardlaw, J.M.; Starr, J.M.; Marioni, R.E.; Deary, I.J. Epigenetic signatures of smoking associate with cognitive function, brain structure, and mental and physical health outcomes in the Lothian Birth Cohort 1936. Transl. Psychiatry 2019, 9, 248. [CrossRef]

57. Joubert, B.R.; Håberg, S.E.; Bell, D.A.; Nilsen, R.M.; Vollset, S.E.; Midttun, O.; Ueland, P.M.; Wu, M.C.; Nystad, W.; Peddada, S.D.; et al. Maternal smoking and DNA methylation in newborns: In utero effect or epigenetic inheritance? Cancer Epidemiol. Biomark. Prev. 2014, 23, 1007-1017. [CrossRef] [PubMed]

58. Su, D.; Wang, X.; Campbell, M.R.; Porter, D.K.; Pittman, G.S.; Bennett, B.D.; Wan, M.; Englert, N.A.; Crowl, C.L.; Gimple, R.C.; et al. Correction: Distinct Epigenetic Effects of Tobacco Smoking in Whole Blood and among Leukocyte Subtypes. PLoS ONE 2017, 12, e0178308. [CrossRef]

59. Ooshio, T.; Irie, K.; Morimoto, K.; Fukuhara, A.; Imai, T.; Takai, Y. Involvement of LMO7 in the association of two cell-cell adhesion molecules, nectin and E-cadherin, through afadin and alpha-actinin in epithelial cells. J. Biol. Chem. 2004, 279, 31365-31373. [CrossRef]

60. Ott, E.B.; van den Akker, N.M.; Sakalis, P.A.; Gittenberger-de Groot, A.C.; Te Velthuis, A.J.; Bagowski, C.P. The lim domain only protein 7 is important in zebrafish heart development. Dev. Dyn. 2008, 237, 3940-3952. [CrossRef]

61. Karlsson, T.; Kvarnbrink, S.; Holmlund, C.; Botling, J.; Micke, P.; Henriksson, R.; Johansson, M.; Hedman, H. LMO7 and LIMCH1 interact with LRIG proteins in lung cancer, with prognostic implications for early-stage disease. Lung Cancer 2018, 125, 174-184. [CrossRef]

62. Jassal, B.; Matthews, L.; Viteri, G.; Gong, C.; Lorente, P.; Fabregat, A.; Sidiropoulos, K.; Cook, J.; Gillespie, M.; Haw, R.; et al. The reactome pathway knowledgebase. Nucleic Acids Res. 2020, 48, D498-D503. [CrossRef] [PubMed]

63. Lao, D.H.; Esparza, M.C.; Bremner, S.N.; Banerjee, I.; Zhang, J.; Veevers, J.; Bradford, W.H.; Gu, Y.; Dalton, N.D.; Knowlton, K.U.; et al. Lmo7 is dispensable for skeletal muscle and cardiac function. Am. J. Physiol. Cell. Physiol. 2015, 309, C470-C479. [CrossRef] [PubMed]

64. Semenova, E.; Wang, X.; Jablonski, M.M.; Levorse, J.; Tilghman, S.M. An engineered 800 kilobase deletion of Uchl3 and Lmo7 on mouse chromosome 14 causes defects in viability, postnatal growth and degeneration of muscle and retina. Hum. Mol. Genet. 2003, 12, 1301-1312. [CrossRef]

65. Holaska, J.M.; Rais-Bahrami, S.; Wilson, K.L. LMO7 is an emerin-binding protein that regulates the transcription of emerin and many other muscle-relevant genes. Hum. Mol. Genet. 2006, 15, 3459-3472. [CrossRef] 